\title{
Characterization of Extensive Microstructural Variations Associated with Punctate White Matter Lesions in Preterm Neonates
}

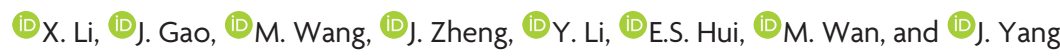

\begin{abstract}
BACKGROUND AND PURPOSE: Punctate white matter lesions are common in preterm neonates. Neurodevelopmental outcomes of the neonates are related to the degree of extension. This study aimed to characterize the extent of microstructural variations for different punctate white matter lesion grades.
\end{abstract}

MATERIALS AND METHODS: Preterm neonates with punctate white matter lesions were divided into 3 grades (from mild to severe: grades I-III). DTI-derived fractional anisotropy, axial diffusivity, and radial diffusivity between patients with punctate white matter lesions and controls were compared with Tract-Based Spatial Statistics and tract-quantification methods.

RESULTS: Thirty-three preterm neonates with punctate white matter lesions and 33 matched controls were enrolled. There were 15, 9, and 9 patients, respectively, in grades I, II, and III. Punctate white matter lesions were mainly located in white matter adjacent to the lateral ventricles, especially regions lateral to the trigone, posterior horns, and centrum semiovale and/or corona radiata. Extensive microstructural changes were observed in neonates with grade III punctate white matter lesions, while no significant changes in DTI metrics were found for grades I and II. A pattern of increased axial diffusivity, increased radial diffusivity, and reduced/unchanged fractional anisotropy was found in regions adjacent to punctate white matter lesion sites seen on TIWI and T2WI. Unchanged axial diffusivity, increased radial diffusivity, and reduced/unchanged fractional anisotropy were observed in regions distant from punctate white matter lesion sites.

CONCLUSIONS: White matter microstructural variations were different across punctate white matter lesion grades. Extensive change patterns varied according to the distance to the lesion sites in neonates with severe punctate white matter lesions. These findings may help in determining the outcomes of punctate white matter lesions and selecting treatment strategies.

ABBREVIATIONS: $A D=$ axial diffusivity; $\mathrm{CST}=$ corticospinal tract; $\mathrm{FA}=$ fractional anisotropy $\mathrm{GCC}=$ genu of the corpus callosum; IFO = inferior fronto-occipital fasciculus; $\mathrm{OR}=$ optic radiation; $\mathrm{PWML}=$ punctate white matter lesion; $\mathrm{RD}=$ radial diffusivity; $\mathrm{SCC}=$ splenium of corpus callosum

$\mathbf{P}$ unctate white matter lesions (PWMLs) are common in neonates and have been found in $>20 \%$ of preterm neonates ( $<37$ weeks of gestation). ${ }^{1-5}$ These lesions may cause severe neu-

Received July 27, 2016; accepted after revision January 26, 2017.

From the Department of Radiology (X.L., J.G., M. Wang, Y.L., J.Y.) and Clinical Research Center (J.Z.), the First Affiliated Hospital, Xi'an, Shaanxi, China; Department of Biomedical Engineering (X.L., M. Wan, J.Y.), the Key Laboratory of Biomedical Information Engineering of the Ministry of Education, School of Life Science and Technology, Xi'an Jiaotong University, Xi'an, China; and Department of Diagnostic Radiology (E.S.H.), University of Hong Kong, Hong Kong, China.

Xianjun Li and Jie Gao contributed equally to this work.

This work was supported by grants from the National Natural Science Foundation of China (No.81171317, 81471631), the National Key Research and Development Program of China (2016YFC0100300), and the 2011 New Century Excellent Talent Support Plan from the Ministry of Education of China (NCET-11-0438).

Please address correspondence to Jian Yang, PhD, Department of Radiology, The First Affiliated Hospital, Xi'an Jiaotong University, Xi'an, Shaanxi, China; e-mail: cjr.yangjian@vip.163.com

-- Indicates open access to non-subscribers at www.ajnr.org

http://dx.doi.org/10.3174/ajnr.A5226 rologic disorders, such as cerebral palsy. ${ }^{2,4}$ PWMLs can be identified on conventional MR imaging as hyperintensity on T1WI and hypointensity on T2WI. ${ }^{1-3,6}$ PWMLs without cystic lesions can be divided into 3 grades. ${ }^{6}$ The grading scale ascends in severity on the basis of the number, size, and distribution of cerebral white matter lesions. Extensive microstructural alterations in white matter beyond the PWMLs visible on conventional MR imaging have been observed. ${ }^{3}$ The neurodevelopmental outcome of neonates is related to the degree of extension associated with PWMLs. ${ }^{7,8}$ However, little is known about the extent of microstructural variations for different PWML grades. More detail is needed regarding the size ranges, shapes, and locations of neonatal/infantile PWMLs, PWML diffusion characteristics, and the distinction between hemorrhagic and nonhemorrhagic PWMLs. ${ }^{9}$

DTI could provide quantitative metrics that reveal microstructural alterations associated with lesions. ${ }^{10,11}$ DTI metrics, especially directional diffusivities, are sensitive to underlying histopathologic processes. ${ }^{12}$ Several methods for analyzing DTI data 
have been proposed. Tract-Based Spatial Statistics (TBSS; http:// fsl.fmrib.ox.ac.uk/fsl/fslwiki/TBSS) is an automated approach for assessing alterations on major white matter tracts. ${ }^{13}$ The tract quantification method was proposed to characterize the location of alterations in white matter. ${ }^{14}$ These automated quantified methods have been used to detect variations due to brain development or injury ${ }^{3,13-15}$ and may enable characterization of alterations associated with PWMLs.

The goal of this study was to explore white matter microstructural variations associated with PWMLs of different grades in preterm neonates and to characterize the change in microstructural patterns along white matter tracts.

\section{MATERIALS AND METHODS}

This is a cross-sectional and observational study. It was approved by the institutional review board of the First Affiliated Hospital of Xi' an Jiaotong University. The parents of the neonates were informed of the risks of MR imaging and gave written consent.

\section{Subjects}

Preterm neonates were enrolled from the neonatal intensive care unit of the First Affiliated Hospital of Xi'an Jiaotong University, from January 2011 to October 2012. During this period, the care, management, MR imaging scanner, and sequences did not change. The inclusion criterion was evidence of punctate lesions in cerebral white matter, which presented as hyperintensity on T1WI and hypointensity on T2WI. Subjects with a clinical diagnosis of congenital malformations of the central nervous system, infections, metabolic disorders, hydrocephalus, gray matter lesions, or major destructive white matter lesions such as cystic degeneration and infarction were excluded. Brain MR imaging was also performed on preterm neonates with comorbid conditions of neonatal asphyxia, hypocalcemia, aspiration pneumonia, and so forth. The preterm neonates without any MR imaging abnormality and matched for sex, gestational age, postnatal age at MR imaging, and birth weight were selected as controls.

\section{MR Imaging Acquisition}

The MR imaging datasets used in this study were acquired for clinical examination and diagnosis. To reduce head movement and complete the MR imaging procedure, we sedated patients with a relatively low dose of oral chloral hydrate $(25-50 \mathrm{mg} / \mathrm{kg}) .{ }^{16}$ Patient selection, monitoring, and management were performed following the "Guidelines for Monitoring and Management of Pediatric Patients during and after Sedation for Diagnostic and Therapeutic Procedures: An Update." ${ }^{17}$ Neonates were laid in a supine position and snugly swaddled in blankets. A pediatrician was present during the MR imaging. Micro earplugs were placed bilaterally in the external acoustic meatuses of the subjects to protect their hearing. The subjects' heads were immobilized by molded foam. Temperature, heart rate, and oxygen saturation were monitored throughout the procedure.

Three-dimensional fast spoiled gradient-recalled echo T1WI, fast spin-echo T2WI, and single-shot echo-planar DTI were performed on a 3T scanner (Signa HDXT; GE Healthcare, Milwaukee, Wisconsin) with an 8-channel head coil. The other parameters for
DTI were the following: 35 gradient directions; b-values $=0$ and $1000 \mathrm{~s} / \mathrm{mm}^{2} ; \mathrm{TR} / \mathrm{TE}=5500 / 95-105 \mathrm{~ms}$; section thickness $=4$ $\mathrm{mm}$ without a gap; $\mathrm{FOV}=180 \times 180 \mathrm{~mm}^{2} ;$ matrix size $=128 \times$ 128 ; and voxel size $=1.41 \times 1.41 \times 4 \mathrm{~mm}^{3}$.

\section{MR Imaging Interpretation}

To provide clues for the etiology of PWMLs, the comorbid conditions of neonates were recorded by the clinician from the neonatal intensive care unit of the institution. Two radiologists, blinded to the clinical history of the neonates, independently analyzed the MR imaging. Both of the radiologists had $>10$ years of experience in the interpretation of the neonatal brain MR imaging. Neonates with PWML were grouped into grades I, II, and III (from mild to severe) by using the following MR imaging grading $\operatorname{method}^{6}$ : grade I: 1 or 2 relatively small lesions (diameter, $\leq 3$ $\mathrm{mm}$ ); grade II: a) $\geq 3$ lesions, or b) 1 large lesion (diameter, $\geq 5$ $\mathrm{mm}$ ); and grade III: a) $\geq 3$ lesions, and b) multiple large lesions (diameter, $\geq 5 \mathrm{~mm}$ ). The locations of PWMLs were recorded as follows: anterior region (anterior to the frontal horn of the lateral ventricles), central region (between the frontal horn and the trigon of the lateral ventricles), and posterior region (posterior to the trigon of the lateral ventricles). ${ }^{1}$ The lesion load in the aforementioned regions was calculated separately. Lesions longer than $5 \mathrm{~mm}$ were segmented into subsections in units of $5 \mathrm{~mm}$. Every subsection was counted while we calculated the lesion load.

\section{Preprocessing of DTI Data}

DTI data were processed by using the FMRIB software library (FSL; http://www.fmrib.ox.ac.uk/fsl). ${ }^{18}$ First, the eddy current correction was performed. Then, brain regions were extracted by using the FSL Brain Extraction Tool (http://fsl.fmrib.ox.ac.uk/fsl/ fslwiki/BET). To exclude the influence of artifacts, we rejected artifact-corrupted volumes (directions) automatically before the tensor estimation. ${ }^{19}$ The number of rejected volumes varied across subjects (median $=2$; range, $0 \sim 11$ ). DTI metrics of fractional anisotropy (FA), axial diffusivity (AD), and radial diffusivity (RD) were calculated by using the FMRIB Diffusion Toolbox (http://fsl.fmrib.ox.ac.uk/fsl/fslwiki/FDT).

Image registration was performed by using an optimized protocol. ${ }^{20,21}$ First, the group mean FA image in native space was created from the subjects in this study. This method was described in a previous atlas creation study. ${ }^{22}$ Second, images of all the subjects were registered to the group mean image. The single-subject FA image with the minimum mean displacement score was selected as the final target. ${ }^{13,20}$ Finally, all individual FA images were registered to the target by using a combination of linear and nonlinear registration methods. ${ }^{20}$ Other metrics were normalized into the target space by using the deformation parameters of FA.

\section{Voxelwise Analysis of TBSS}

The normalized individual FA images were up-sampled to a voxel size of $1 \times 1 \times 1 \mathrm{~mm}^{3}$ and then were averaged to create the mean FA. ${ }^{13}$ A mean FA skeleton was extracted from the mean FA to represent the center of white matter tracts. ${ }^{13}$ The threshold of the FA skeleton was 0.15 . DTI metrics were projected onto this skeleton. 
Table 1: Demographics of preterm neonates with PWMLs and controls ${ }^{a}$

\begin{tabular}{|c|c|c|c|c|c|c|c|c|c|}
\hline & $\begin{array}{l}\text { PWML Grade I } \\
(n=15)\end{array}$ & $\begin{array}{l}\text { Controls } \\
(n=15)\end{array}$ & $\begin{array}{c}P \\
\text { Value }\end{array}$ & $\begin{array}{l}\text { PWML Grade II } \\
(n=9)\end{array}$ & $\begin{array}{c}\text { Controls } \\
(n=9)\end{array}$ & $\begin{array}{c}P \\
\text { Value }\end{array}$ & $\begin{array}{l}\text { PWML Grade III } \\
(n=9)\end{array}$ & $\begin{array}{c}\text { Controls } \\
(n=9)\end{array}$ & $\begin{array}{c}P \\
\text { Value }\end{array}$ \\
\hline GA (wk) & $\begin{array}{c}34+2 \\
(32+0 \sim 35+6)\end{array}$ & $\begin{array}{c}34+1 \\
(32+6 \sim 36+2)\end{array}$ & .21 & $\begin{array}{c}33+6 \\
(30+5 \sim 34+5)\end{array}$ & $\begin{array}{c}33+6 \\
(30+1 \sim 35+0)\end{array}$ & .76 & $\begin{array}{c}33+0 \\
(32+3 \sim 35+4)\end{array}$ & $\begin{array}{c}33+2 \\
(32+1 \sim 35+6)\end{array}$ & .37 \\
\hline $\begin{array}{l}\text { Postnatal age at } \\
\text { scan (days) }\end{array}$ & $\begin{array}{c}8 \\
(1 \sim 13)\end{array}$ & $\begin{array}{c}8 \\
(1 \sim 13)\end{array}$ & .53 & $\begin{array}{c}10 \\
(6 \sim 14)\end{array}$ & $\begin{array}{c}10 \\
(8 \sim 14)\end{array}$ & .67 & $\begin{array}{c}10 \\
(4 \sim 13)\end{array}$ & $\begin{array}{c}9 \\
(1 \sim 14)\end{array}$ & .80 \\
\hline PMA (wk) & $\begin{array}{c}35+5 \\
(33+1 \sim 37+2)\end{array}$ & $\begin{array}{c}36+0 \\
(33+3 \sim 37+1)\end{array}$ & .32 & $\begin{array}{c}35+3 \\
(32+1 \sim 36+0)\end{array}$ & $\begin{array}{c}35+1 \\
(32+1 \sim 36+4)\end{array}$ & .23 & $\begin{array}{c}34+5 \\
(33+1 \sim 36+3)\end{array}$ & $\begin{array}{c}35+2 \\
(32+5 \sim 36+5)\end{array}$ & .40 \\
\hline Birth weight (g) & $\begin{array}{c}1780 \\
(1470 \sim 2360)\end{array}$ & $\begin{array}{c}1760 \\
(1410 \sim 2400)\end{array}$ & .22 & $\begin{array}{c}1950 \\
(1480 \sim 2700)\end{array}$ & $\begin{array}{c}1750 \\
(1460 \sim 2360)\end{array}$ & .26 & $\begin{array}{c}1920 \\
(1650 \sim 2760)\end{array}$ & $\begin{array}{c}1700 \\
(1460 \sim 2570)\end{array}$ & .51 \\
\hline Sex (male/female) & 10:5 & $10: 5$ & - & $4: 5$ & $4: 5$ & - & $3: 6$ & $3: 6$ & - \\
\hline
\end{tabular}

Note:-GA indicates gestational age; PMA, postmenstrual age.

${ }^{a}$ GA, PMA, and birth weight values are medians (ranges). Values in the row of sex are subject numbers. Wilcoxon signed rank tests were used to test the group difference between each grade of PWML and its matched control group due to non-normal distributions of variables. The sex ratios were not tested because they were the same in PWML and the corresponding control groups.

Table 2: Clinical history of subjects

\begin{tabular}{lccccc} 
& \multicolumn{3}{c}{ No. of Subjects (Column-Based Percentage) } & \\
\cline { 2 - 5 } & $\begin{array}{c}\text { All Grades } \\
(\boldsymbol{n}=33)\end{array}$ & $\begin{array}{c}\text { Grade I } \\
(\boldsymbol{n}=15)\end{array}$ & $\begin{array}{c}\text { Grade II } \\
(\boldsymbol{n}=9)\end{array}$ & $\begin{array}{c}\text { Grade III } \\
(\boldsymbol{n}=9)\end{array}$ & $\begin{array}{c}\text { Controls } \\
(\boldsymbol{n}=33)\end{array}$ \\
\cline { 1 - 5 } Hypoxic-ischemic encephalopathy & $20(61 \%)$ & $7(47 \%)$ & $5(56 \%)$ & $8(89 \%)$ & $0(0 \%)$ \\
Neonatal asphyxia & $17(52 \%)$ & $7(47 \%)$ & $3(33 \%)$ & $7(78 \%)$ & $7(21 \%)$ \\
Neonatal respiratory distress & $13(40 \%)$ & $4(27 \%)$ & $3(33 \%)$ & $6(67 \%)$ & $6(18 \%)$ \\
$\quad$ syndrome & $11(33 \%)$ & $6(40 \%)$ & $2(22 \%)$ & $3(33 \%)$ & $2(6 \%)$ \\
Neonatal pneumonia & $10(30 \%)$ & $4(27 \%)$ & $4(44 \%)$ & $2(22 \%)$ & $0(0 \%)$ \\
Electrolyte disturbances & $9(27 \%)$ & $4(27 \%)$ & $3(33 \%)$ & $2(22 \%)$ & $4(12 \%)$ \\
Neonatal anemia & $8(24 \%)$ & $3(20 \%)$ & $2(22 \%)$ & $3(33 \%)$ & $7(21 \%)$ \\
Metabolic acidosis & $6(18 \%)$ & $3(20 \%)$ & $0(0 \%)$ & $3(33 \%)$ & $3(9 \%)$ \\
Congenital heart disease & $4(12 \%)$ & $0(0 \%)$ & $2(22 \%)$ & $2(22 \%)$ & $1(3 \%)$ \\
Neonatal hypoglycemia & $4(12 \%)$ & $0(0 \%)$ & $2(22 \%)$ & $2(22 \%)$ & $0(0 \%)$ \\
Neonatal intracranial hemorrhage & $2(6 \%)$ & $0(0 \%)$ & $1(11 \%)$ & $1(11 \%)$ & $0(0 \%)$ \\
Neonatal polycythemia & $2(6 \%)$ & $1(7 \%)$ & $1(11 \%)$ & $0(0 \%)$ & $6(18 \%)$ \\
Hyperbilirubinemia & $1(3 \%)$ & $0(0 \%)$ & $1(11 \%)$ & $0(0 \%)$ & $0(0 \%)$ \\
Agenesis of bronchus & $0(0 \%)$ & $0(0 \%)$ & $0(0 \%)$ & $0(0 \%)$ & $9(27 \%)$ \\
Neonatal hypocalcemia & $0(0 \%)$ & $0(0 \%)$ & $0(0 \%)$ & $0(0 \%)$ & $7(21 \%)$ \\
Aspiration pneumonia & & & & & \\
\hline
\end{tabular}

jects were normalized to the neonatal template. $^{22}$ Second, measurement planes were equally spaced ${ }^{14}$ on the tract probabilistic map (cmrm.med.jhmi.edu) for the neonatal template. ${ }^{22}$ Measurements were then averaged on each plane. ${ }^{14} \mathrm{Fi}$ nally, DTI metrics were measured at 100 equivalent levels. ${ }^{15}$ The combination of changes in DTI metrics was used to characterize damage types. ${ }^{12}$

\section{Statistical Analysis}

Each case was matched with a control by sex (the same sex in PWML and control groups), gestational age (differences, $<1$ week), postnatal age at scanning (differences, $<5$ days), and birth weight (differences, $<0.5 \mathrm{~kg}$ ). Because case and control groups were dependent after matching,

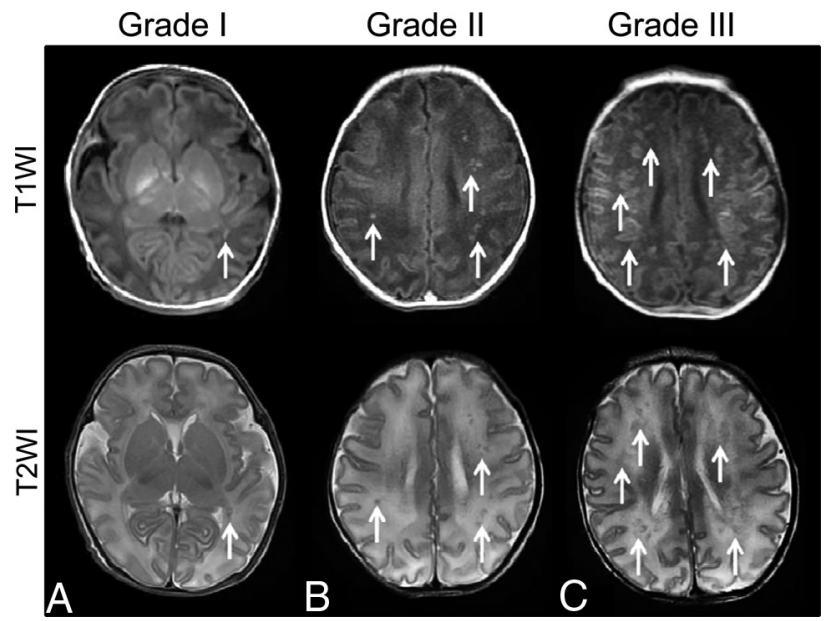

FIG 1. The appearances of 3 PWML grades (A, grade I; $B$, grade II; $C$, grade III) on TIWI and T2WI.

\section{Tract-Quantification Analysis}

To characterize the change patterns along white matter tracts, we quantified the DTI metrics on the representative tracts: projection fibers of the corticospinal tract (CST) and optic radiation (OR); commissural fibers of the splenium of the corpus callosum (SCC) and genu of the corpus callosum (GCC); and association fibers of the inferior fronto-occipital fasciculus (IFO). First, images of all sub-
Wilcoxon signed rank tests were used for the group difference in demographics between each grade of PWML and its matched control group due to non-normal distributions of variables. $\kappa$ tests and intraclass correlation coefficients were used to determine intrarater and interrater agreement for the PWML grading and the lesion number respectively. $P<.05$ was significant for the above analyses.

The lesion number was counted repeatedly in anterior, central, and posterior regions for each PWML subject. The Friedman test was used to assess the variation of lesion number across regions. Then pair-wise comparisons among the 3 regions were performed by using Wilcoxon signed rank tests. $P<.017(.05 / 3)$ was considered significant after the Bonferroni correction. The analyses above were performed by using SPSS (Version 17.0; IBM, Armonk, New York).

The FSL Randomize tool (http://fsl.fmrib.ox.ac.uk/fsl/fslwiki/ Randomise/UserGuide) was used for the voxelwise analysis to compare PWML groups and controls. The number of permutations was 10,000 . Tests in TBSS were considered significant at $P<.05$ after the threshold-free cluster enhancement and family-wise error rate correction.

In tract-quantification analysis, the Wilcoxon signed rank test in MATLAB (Version 7.11; MathWorks, Natick, Massachusetts) was used to evaluate differences in regional values of DTI metrics between PWML groups and controls. $P<.05$ was considered significant for this analysis. 
Table 3: Lesion load of PWMLs in the anterior, central, and posterior regions ${ }^{\mathrm{a}}$

\begin{tabular}{cccccccc}
\hline & \multicolumn{2}{c}{ Lesion No. (Median and Range) } & & \multicolumn{3}{c}{$P$ Value } \\
\cline { 2 - 3 } Grade & Anterior & Central & Posterior & & $\begin{array}{c}\text { Anterior vs } \\
\text { Central }\end{array}$ & $\begin{array}{c}\text { Central vs } \\
\text { Posterior }\end{array}$ & $\begin{array}{c}\text { Anterior vs } \\
\text { Posterior }\end{array}$ \\
\hline I I & $0(0 \sim 0)$ & $0(0 \sim 1)$ & $1(1 \sim 2)$ & & .32 & $<.001^{b, c}$ & $<.001^{\mathrm{b}, c}$ \\
II & $0(0 \sim 6)$ & $1(0 \sim 9)$ & $5(3 \sim 12)$ & & .17 & $.02^{\mathrm{b}}$ & $<.01^{\mathrm{b}, \mathrm{c}}$ \\
III & $8(2 \sim 18)$ & $24(5 \sim 38)$ & $16(12 \sim 29)$ & $<.01^{\mathrm{b}, \mathrm{c}}$ & .37 & $.01^{\mathrm{b}, \mathrm{c}}$ \\
\hline
\end{tabular}

${ }^{a}$ The inter-region comparisons were performed with the Wilcoxon signed rank test after the Friedman test. The anterior region is anterior to the frontal horn of the lateral ventricles. The central region is between the frontal horn and the trigon of the lateral ventricles. The posterior region is posterior to the lateral ventricles.

$p<.05$.

${ }^{c} P<.017(.05 / 3)$, significant after the Bonferroni correction.

\section{Severe PWML (grade III) vs. control}

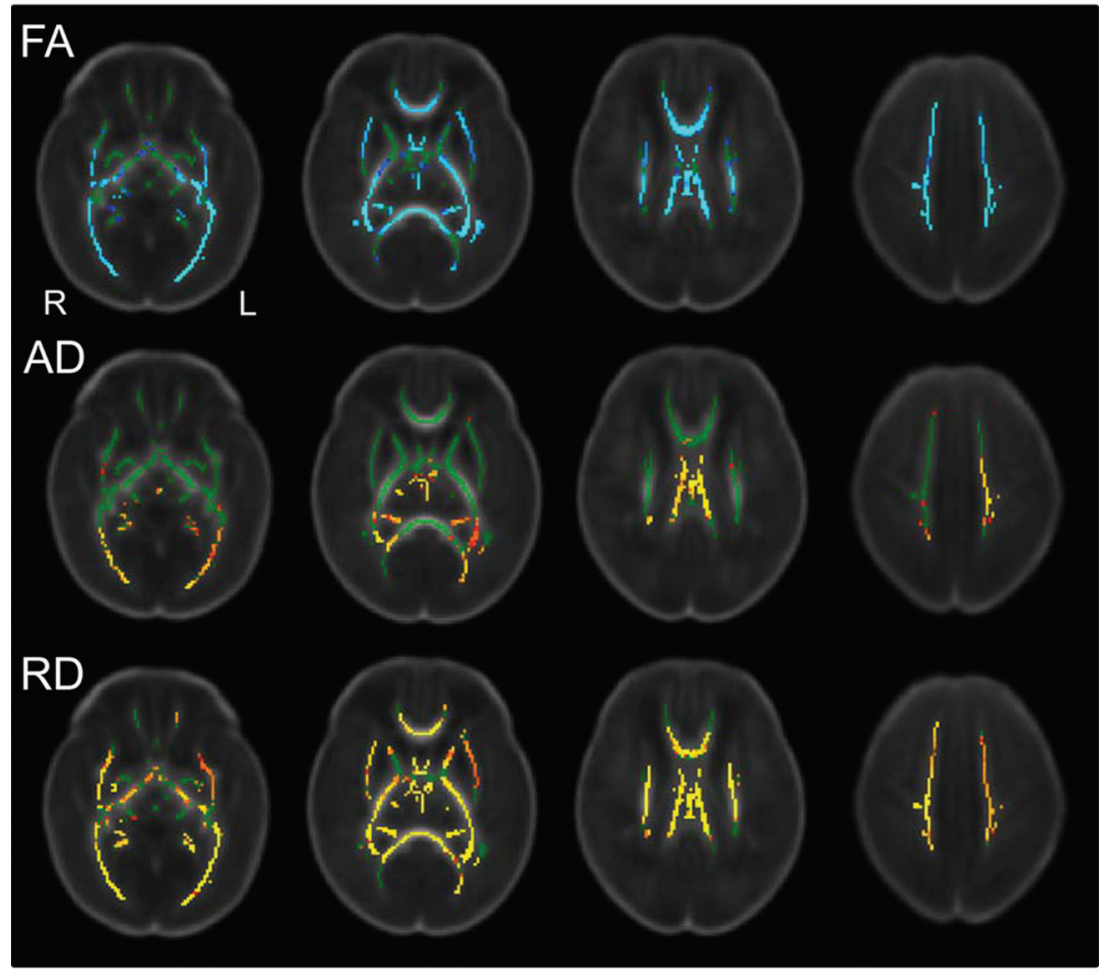

\begin{tabular}{ll|l}
\hline 0.05 & 0 & $P$ values for $\mathrm{PWML}<$ control neonates \\
\hline 0.05 & 0 & $P$ values for $\mathrm{PWML}>$ control neonates
\end{tabular}

FIG 2. Changes in DTI metrics (FA, AD, and RD) in preterm neonates with severe PWMLs compared with controls revealed by TBSS (there were no significant changes in neonates with PWML grades I and II). Green regions represent the mean FA skeleton without any significant differences. Significant decreases in neonates with PWMLs compared with controls are shown in cool colors (blue and light blue). Significant increases in neonates with PWMLs compared with controls are shown in warm colors (red and yellow).

\section{RESULTS}

\section{Demographics}

Thirty-three preterm neonates with PWMLs and 33 matched controls were enrolled. The intrarater and interrater agreement for PWML grading was 97\% $(\kappa$ value $=0.953$; standard error $=$ $0.906)$ and $93.3 \%(\kappa$ value $=0.906$; standard error $=0.063)$, respectively. Fifteen, 9, and 9 neonates with PWMLs were classified into grades I, II, and III, respectively. No significant differences in gestational age, postnatal age at MR imaging, postmenstrual age, or birth weight were found between neonates with PWMLs and controls (Table 1). In this study, PWMLs were associated with many comorbid conditions (Table 2). More than half of the neonates with PWMLs had a clinical history of hypoxic-ischemic encephalopathy $(61 \%)$ and neonatal asphyxia (52\%).

\section{PWML Location}

PWMLs were mainly located in the white matter adjacent to lateral ventricles, especially the regions lateral to the trigone, posterior horns, and the centrum semiovale and/or corona radiata (Fig 1). The intrarater and interrater correlation coefficients for the lesion number counting were 0.994 ( $95 \%$ confidence interval, $0.989 \sim 0.997$ ) and 0.974 (95\% confidence interval, 0. 948 0. 987), respectively. For grades I and II, most of the lesions were located in the posterior region (Table 3 ). For grade III, more lesions were located in the central and posterior regions than in the anterior region (Table 3 ).

\section{Microstructural Alterations in Different PWML Grades}

The extent of microstructural alterations was different across PWML grades. There were no significant changes in grades I and II compared with controls $(P \geq .05)$. For neonates with PWML grade III, reduced $\mathrm{FA}$, increased $\mathrm{AD}$, and increased $\mathrm{RD}$ were observed in the centrum semiovale and/or corona radiata, white matter near the trigone of the lateral ventricles, SCC, and OR (Fig 2). These regions were near PWML sites seen on T1WI and T2WI (Fig 1). Reduced FA, unchanged $\mathrm{AD}$, and increased $\mathrm{RD}$ were observed in regions distant from the lesion sites, including the CST in the posterior limb of the internal capsule, more extensive areas in the $\mathrm{OR}$, and the central part of the SCC, GCC, IFO, and the external capsule (Fig 2).

\section{Microstructural Alterations along Tracts}

Different patterns of microstructural changes associated with severe PWMLs (grade III) were found along white matter tracts (Fig 3). Increased AD, increased RD, and reduced/unchanged FA were found in the superior part of the CST, the occipital proximal region of the OR, the peripheral regions of the SCC near the lateral ventricles, the anterior and posterior regions of the left IFO, and the anterior region of the right IFO. Unchanged $\mathrm{AD}$, increased $\mathrm{RD}$, and unchanged/reduced FA were observed in the posterior limb of the internal capsule part of the CST, the region of the OR proximal to the thalamus, central regions of the SCC and GCC, the central region of the left IFO, and the central and posterior regions of the right IFO. 

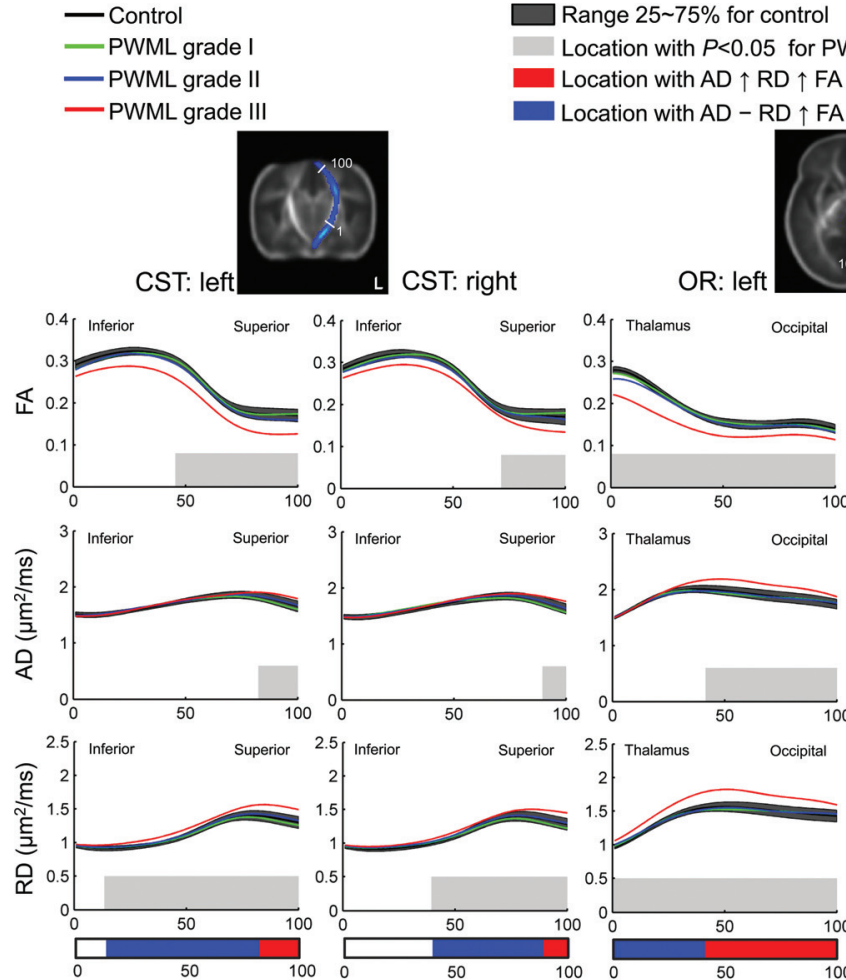

OR: left
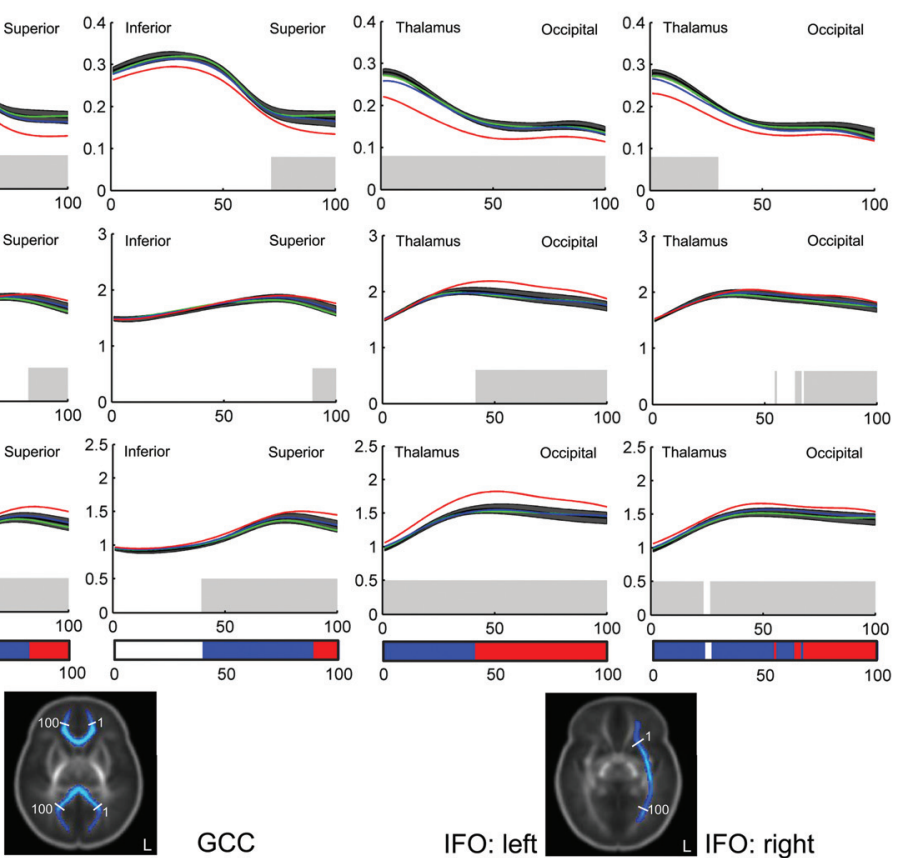

SCC GCC
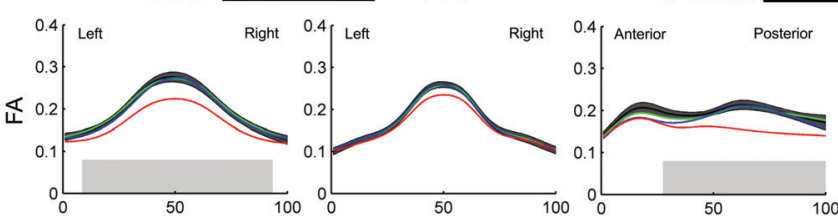

IFO: I
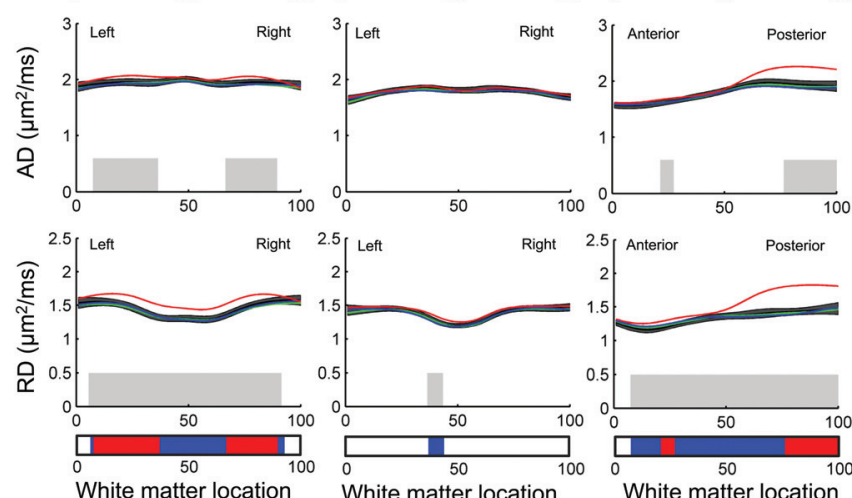

White matter location
White matter location
PWML grade III vs. control $\downarrow /-$
OR: right

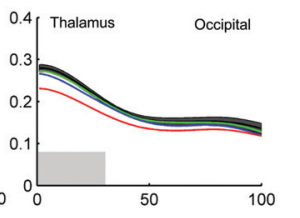

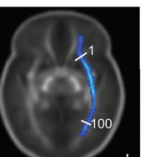

FIG 3. Changes in DTI metrics (FA, AD, and RD) along white matter tracts in preterm neonates with PWML grades I, II, and III compared with controls.

\section{DISCUSSION}

The results demonstrated different levels of microstructural alterations across the 3 PWML grades. Extensive white matter alterations were revealed by DTI metrics in neonates with PWML grade III. There were 2 main patterns of alterations found with DTI. The distribution of alterations was related to the distance to lesions visible on the conventional MR imaging.

The etiology of PWMLs is nonspecific. ${ }^{8}$ PWMLs were associated with various comorbid conditions in this study (Table 2).
Knowledge of the pathogenesis of PWMLs is limited. ${ }^{7}$ Evidence has revealed that PWMLs may correspond to vascular congestion with infiltration of activated microglia. ${ }^{8}$ Late myelination defects indicate that gliosis and/or loss of oligodendrocytes is possible. ${ }^{7}$ Although the etiology and pathogenesis are nonspecific and complex, the location of PWMLs is regular.

\section{PWML Location}

PWMLs were common along the corona radiata, in the posterior periventricular white matter, and along the OR. This finding is consistent with previous ones. $^{7,8,23}$ The distribution of injury is in agreement with areas of high microglia density and deep medullary venous anatomy. $^{7,23}$ Microglia accumulate in restricted laminar bands, most notably around 19-30 gestational weeks, at the axonal crossroads in the centrum semiovale, extending caudally in the immature white matter to the OR. ${ }^{24}$ The most vulnerable area is the region of the terminal veins, which is a collection of medullary veins in the posterior frontal, central, and parietal regions. ${ }^{23}$ In summary, metabolic demand and regional cerebral blood flow contribute to the distribution of the white matter lesions. ${ }^{25}$

\section{Extensive Microstructural Alterations in Different PWML Grades}

The developmental outcome of PWMLs is related to the degree of extension. ${ }^{7,8}$ The results in this study reveal that extensive microstructural changes were different across PWML grades. This finding may be due to different pathophysiologic mechanisms ${ }^{2,6}$ or different effects on brain development. ${ }^{2}$ Rare isolated PWMLs can disappear during brain development and leave no residual abnormality. ${ }^{3,7,26,27}$ We found that there were no extensive microstructural alterations associated with PWML grades I and II. Several studies have shown that PWML-related alterations extend beyond the immediate area of injury. ${ }^{3,28}$ Extensive microstructural alterations were revealed here in neonates with severe PWMLs. Relatively larger lesions leave areas of hypomyelination, which may relate to focal gliosis, oligodendroglial injury, or axonal swelling in lesion sites. ${ }^{2,6,7}$ A cross-talk exists between axons and oligodendrocytes during development. ${ }^{29}$ This cross-talk maintains proper metabolic function of axons, trophic support, cytoskeletal arrangement, ion channel organiza- 
tion, and axonal transport. ${ }^{29}$ Damage to axons or glial cells in PWML sites would affect healthy cross-talk between the axons and the oligodendrocytes along the tract. This may influence the proliferation of oligodendrocyte precursor cells and further myelination, even in areas distant from the lesion sites.

In this study, severe PWML-related alterations were widespread along various white matter tracts, including the CST, OR, SCC, GCC, and IFO. The corticospinal tracts are the major projectional motor fibers of the brain. It has been found that altered structural integrity in the CST may result in delayed psychomotor development, ${ }^{30}$ motor impairment, ${ }^{8}$ and cerebral palsy. ${ }^{30,31}$ High rates of motor impairment or cerebral palsy have been found in subjects with PWMLs. ${ }^{2,8}$ Visual function in preterm neonates at term-equivalent age is directly related to the development of white matter in the OR. ${ }^{32}$ In agreement with previous findings, PWMLs are often present in the OR and may be associated with impaired visual function. ${ }^{4,8}$ The corpus callosum is the primary center for the interhemispheric integration of information. ${ }^{33}$ Pictogram test performance, ${ }^{34}$ Psychomotor Developmental Index scores, ${ }^{30}$ and the speed of bimanual motor coordination ${ }^{33}$ are related to the structural integrity of the SCC. The development of the GCC is involved in the maturation of semantic coding, ${ }^{34}$ intelligence, ${ }^{35}$ and visual learning, possibly through a higher level integration of visual information relayed to the frontal lobes by the IFO. ${ }^{36}$ The IFO connects the occipital lobe with the frontal cortex, playing a critical role in neurocognitive maturation of processing speed, visual learning, ${ }^{36}$ and semantic processing. ${ }^{37}$ The widespread alterations in projection, commissural, and association fibers associated with PWMLs may result in motor, sensory, and cognitive disorders. ${ }^{4,7,8}$

\section{Regional Microstructural Alteration Patterns}

Changes in DTI metrics demonstrated a PWML site-related spatial distribution: significantly increased $\mathrm{AD}$, increased $\mathrm{RD}$, and decreased/unchanged FA in regions adjacent to the PWML sites, with unchanged $\mathrm{AD}$, increased $\mathrm{RD}$, and decreased/unchanged FA in regions distant from the PWML sites. These 2 patterns may be related to different mechanisms underlying the effects of PWMLs on brain development, including the delayed oligodendrocyte proliferation or the death of oligodendrocyte progenitors, and the disturbed maturation of oligodendrocytes. During normal brain development, the proliferation of glial cell bodies is linked to decreases in diffusivity indices in all directions. This process would lead to unchanged or increased FA. ${ }^{38}$ The disrupted cross-talk between an axon and oligodendrocytes would delay the early process of the oligodendrocyte proliferation or lead to the death of oligodendrocyte progenitors. ${ }^{29,39}$ Increases of $\mathrm{AD}$ and $\mathrm{RD}$ in regions adjacent to PWMLs may reveal this process. The increase in $\mathrm{RD}$ without changes in AD could reflect demyelination or dysmyelination. ${ }^{40,41}$ In the regions distant from the lesion sites, the change in $\mathrm{AD}$ was not significant. This finding suggested that maturation of oligodendrocytes was disturbed without loss of oligodendrocytes in these regions. ${ }^{39}$

According to previous studies ${ }^{7,8}$ and one of our ongoing cohort studies, outcomes during infancy and/or preschool age were relevant to the PWML grading and extensive microstructural alterations observed on MR imaging during the neonatal period.
Early intervention is associated with improved outcomes. ${ }^{42}$ Considering that extensive microstructural alterations were different across PWML grades, patients with different PWML grades should be treated with different approaches. Widespread microstructural changes were observed in neonates with PWML grade III. This finding suggests that early multifaceted treatment strategies (including rehabilitation and interventions associated with motor and cognitive competence, and so forth) might be beneficial to patients.

This study had several limitations. Widespread variations were observed in neonates with severe PWMLs. However, only several representative tracts were selected during the tract-quantification analysis. Besides the selected tracts, other structures (superior fronto-occipital fascicle, tapetum, and so forth) would also be vulnerable. The follow-up work is not finished. We will try to verify outcomes of the enrolled subjects in the future work. The sample size of neonates with PWMLs in each group is relatively small. Furthermore, this work is an in vivo study on the human brain. Pathologic experiments are needed to reveal the exact microstructural changes associated with PWMLs.

\section{CONCLUSIONS}

White matter microstructural variations were different across PWML grades. Extensive change patterns varied according to the distance to lesion sites in neonates with severe PWMLs. These findings may help in determining outcomes of PWMLs and selecting appropriate early treatment strategies.

\section{ACKNOWLEDGMENTS}

The authors are grateful to Drs Li Liu, Xihui Zhou, and Xiaoquan $\mathrm{Li}$ in the neonatology department for preparing and monitoring the neonates before and during imaging.

Disclosures: Jian Yang_RELATED: Grant: National Natural Science Foundation of China, Ministry of Education of China, Ministry of Science and Technology of China, Comments: This work was supported by grants from the National Natural Science Foundation of China (No.81171317, 81471631), the National Key Research and Development Program of China (2016YFC0100300), and the 2011 New Century Excellent Talent Support Plan from the Ministry of Education of China (NCET-11-0438). * *Money paid to the institution.

\section{REFERENCES}

1. Tortora D, Panara V, Mattei PA, et al. Comparing 3T T1-weighted sequences in identifying hyperintense punctate lesions in preterm neonates. AJNR Am J Neuroradiol 2015;36:581-86 CrossRef Medline

2. Kersbergen KJ. Different patterns of punctate white matter lesions in serially scanned preterm infants. PLoS One 2014;9:e108904 CrossRef Medline

3. Bassi L, Chew A, Merchant N, et al. Diffusion tensor imaging in preterm infants with punctate white matter lesions. Pediatr Res 2011;69:561-66 CrossRef Medline

4. de Bruïne FT, van den Berg-Huysmans AA, Leijser LM, et al. Clinical implications of MR imaging findings in the white matter in very preterm infants: a 2-year follow-up study. Radiology 2011;261:899906 CrossRef Medline

5. Dyet LE, Kennea N, Counsell SJ, et al. Natural history of brain lesions in extremely preterm infants studied with serial magnetic resonance imaging from birth and neurodevelopmental assessment. Pediatrics 2006;118:536-48 CrossRef Medline

6. Childs AM, Cornette L, Ramenghi LA, et al. Magnetic resonance and cranial ultrasound characteristics of periventricular white matter

AJNR Am J Neuroradiol 38:1228-34 Jun 2017 www.ajnr.org

1233 
abnormalities in newborn infants. Clin Radiol 2001;56:647-55 CrossRef Medline

7. Raybaud C, Ahmad T, Rastegar N, et al. The premature brain: developmental and lesional anatomy. Neuroradiology 2013;55:23-40 CrossRef Medline

8. Rutherford MA, Supramaniam V, Ederies A, et al. Magnetic resonance imaging of white matter diseases of prematurity. Neuroradiology 2010;52:505-21 CrossRef Medline

9. Niwa T, de Vries LS, Benders MJ, et al. Punctate white matter lesions in infants: new insights using susceptibility-weighted imaging. Neuroradiology 2011;53:669-79 CrossRef Medline

10. Le Bihan D, Iima M. Diffusion magnetic resonance imaging: what water tells us about biological tissues. PLoS Biol 2015;13:e1002203 CrossRef Medline

11. Hüppi PS, Murphy B, Maier SE, et al. Microstructural brain development after perinatal cerebral white matter injury assessed by diffusion tensor magnetic resonance imaging. Pediatrics 2001;107: 455-60 CrossRef Medline

12. Wang S, Wu EX, Tam CN, et al. Characterization of white matter injury in a hypoxic-ischemic neonatal rat model by diffusion tensor MRI. Stroke 2008;39:2348-53 CrossRef Medline

13. Smith SM, Jenkinson M, Johansen-Berg H, et al. Tract-based spatial statistics: voxelwise analysis of multi-subject diffusion data. Neuroimage 2006;31:1487-505 CrossRef Medline

14. Groeschel S, Tournier JD, Northam GB, et al. Identification and interpretation of microstructural abnormalities in motor pathways in adolescents born preterm. Neuroimage 2014;87:209-19 CrossRef Medline

15. Yeatman JD, Dougherty RF, Myall NJ, et al. Tract profiles of white matter properties: automating fiber-tract quantification. PLoS One 2012; 7:e49790 CrossRef Medline

16. Bracken J, Heaslip I, Ryan S. Chloral hydrate sedation in radiology: retrospective audit of reduced dose. Pediatr Radiol 2012;42:349-54 CrossRef Medline

17. Coté CJ, Wilson S; American Academy of Pediatrics, American Academy of Pediatric Dentistry, Work Group on Sedation. Guidelines for monitoring and management of pediatric patients during and after sedation for diagnostic and therapeutic procedures: an update. $\mathrm{Pe}$ diatrics 2006;118:2587-602 CrossRef Medline

18. Smith SM, Jenkinson M, Woolrich MW, et al. Advances in functional and structural MR image analysis and implementation as FSL. Neuroimage 2004;23(suppl 1):S208-19 CrossRef Medline

19. Li X, Yang J, Gao J, et al. A robust post-processing workflow for datasets with motion artifacts in diffusion kurtosis imaging. PLoS One 2014;9:e94592 CrossRef Medline

20. Ball G, Counsell SJ, Anjari M, et al. An optimised tract-based spatial statistics protocol for neonates: applications to prematurity and chronic lung disease. Neuroimage 2010;53:94-102 CrossRef Medline

21. Li X, Gao J, Wang M, et al. Rapid and reliable tract-based spatial statistics pipeline for diffusion tensor imaging in the neonatal brain: applications to the white matter development and lesions. Magn Reson Imaging 2016;34:1314-21 CrossRef Medline

22. Oishi K, Mori S, Donohue PK, et al. Multi-contrast human neonatal brain atlas: application to normal neonate development analysis. Neuroimage 2011;56:8-20 CrossRef Medline

23. Raets M, Dudink J, Raybaud C, et al. Brain vein disorders in newborn infants. Dev Med Child Neurol 2015;57:229-40 CrossRef Medline

24. Verney C, Monier A, Fallet-Bianco C, et al. Early microglial colonization of the human forebrain and possible involvement in periventricular white-matter injury of preterm infants. J Anat 2010; 217:436-48 CrossRef Medline
25. Takashima S, Itoh M, Oka A. A history of our understanding of cerebral vascular development and pathogenesis of perinatal brain damage over the past 30 years. Semin Pediatr Neurol 2009;16:226-36 CrossRef Medline

26. Ramenghi LA, Fumagalli M, Righini A, et al. Magnetic resonance imaging assessment of brain maturation in preterm neonates with punctate white matter lesions. Neuroradiology 2007;49:161-67 CrossRef Medline

27. Cornette L, Tanner S, Ramenghi L, et al. Magnetic resonance imaging of the infant brain: anatomical characteristics and clinical significance of punctate lesions. Arch Dis Child Fetal Neonatal Ed 2002; 86:F171-77 CrossRef Medline

28. Miller SP, Vigneron DB, Henry RG, et al. Serial quantitative diffusion tensor MRI of the premature brain: development in newborns with and without injury. J Magn Reson Imaging 2002;16:621-32 CrossRef Medline

29. Alizadeh A, Dyck SM, Karimi-Abdolrezaee S. Myelin damage and repair in pathologic CNS: challenges and prospects. Front $\mathrm{Mol} \mathrm{Neu}$ rosci 2015;8:35 CrossRef Medline

30. Pannek K, Scheck SM, Colditz PB, et al. Magnetic resonance diffusion tractography of the preterm infant brain: a systematic review. Dev Med Child Neurol 2014;56:113-24 CrossRef Medline

31. Jaspers E, Byblow WD, Feys H, et al. The corticospinal tract: a biomarker to categorize upper limb functional potential in unilateral cerebral palsy. Front Pediatr 2015;3:112 CrossRef Medline

32. Bassi L, Ricci D, Volzone A, et al. Probabilistic diffusion tractography of the optic radiations and visual function in preterm infants at term equivalent age. Brain 2008;131:573-82 CrossRef Medline

33. Muetzel RL, Collins PF, Mueller BA, et al. The development of corpus callosum microstructure and associations with bimanual task performance in healthy adolescents. Neuroimage 2008;39:1918-25 CrossRef Medline

34. Kozlovskiy SA, Vartanov AV, Pyasik MM, et al. Functional role of corpus callosum regions in human memory functioning. Int J Psychophysiol 2012;85:396-97 CrossRef

35. Kontis D, Catani M, Cuddy M, et al. Diffusion tensor MRI of the corpus callosum and cognitive function in adults born preterm. Neuroreport 2009;20:424-28 CrossRef Medline

36. Peters BD, Ikuta T, DeRosse P, et al. Age-related differences in white matter tract microstructure are associated with cognitive performance from childhood to adulthood. Biol Psychiatry 2014;75: 248-56 CrossRef Medline

37. Ivanova MV, Isaev DY, Dragoy OV, et al. Diffusion-tensor imaging of major white matter tracts and their role in language processing in aphasia. Cortex 2016;85:165-81 CrossRef Medline

38. Dubois J, Dehaene-Lambertz G, Kulikova S, et al. The early development of brain white matter: a review of imaging studies in fetuses, newborns and infants. Neuroscience 2014;276:48-71 CrossRef Medline

39. Back SA, Riddle A, McClure MM. Maturation-dependent vulnerability of perinatal white matter in premature birth. Stroke 2007;38 724-30 CrossRef Medline

40. Song SK, Yoshino J, Le TQ, et al. Demyelination increases radial diffusivity in corpus callosum of mouse brain. Neuroimage 2005;26: 132-40 CrossRef Medline

41. Song SK, Sun SW, Ramsbottom MJ, et al. Dysmyelination revealed through MRI as increased radial (but unchanged axial) diffusion of water. Neuroimage 2002;17:1429-36 CrossRef Medline

42. Hadders-Algra M, Boxum AG, Hielkema T, et al. Effect of early intervention in infants at very high risk of cerebral palsy: a systematic review. Dev Med Child Neurol 2017;59:246-58 CrossRef Medline 